\title{
An Empirical Study on Business-to- Government Data Exchange Strategies to Reduce the Administrative Costs for Businesses
}

\author{
Rex Arendsen, Tom. M. van Engers, Robbin te Velde \\ Leibniz Center for Law, Faculty for Law, University of Amsterdam, Oude \\ Manhuispoort 4, Postbus 1030, 1000 BA Amsterdam, the Netherlands, \\ rex.arendsen@kpnplanet.nl, VanEngers@uva.nl,www.LeibnizCenter.org. \\ Dialogic Innovation \& Interaction, the Netherlands, tevelde@dialogic.n1, \\ www.dialogic.nl.
}

\begin{abstract}
In recently developed policies the electronic exchange of data with governmental organisations is seen as a means to help reduce the administrative burden for businesses. Even laws have become active to enforce electronic data filing. However, we do not know whether these eGovernment applications do help reduce the administrative burden, so we do not know whether this new legislation is effective either. Although many business-to-government systems are currently being implemented, the adoption of these data interchange systems in a governmental context has not yet been studied extensively. In the study reported in this paper we investigate data exchange related adoption strategies in order to be able to address (in)effective strategies for the reduction of the administrative burden. We present an analysis of adoption factors that influence adoption decisions of SME companies in this context. Based on a representative survey we found some factors that seem to be relevant for the (non)adoption of business-togovernment data exchange systems. We found that especially small companies tend to outsource eGovernment related data exchange processes. Therefore we conclude that it is very unlikely that the governments' aims to reduce administrative burden are met using current implementation strategies. We suggest an adapted strategy.
\end{abstract}

\section{Introduction}

It has been widely acknowledged that inter-organisational information systems (of which EDI systems are an example) reduce communication costs and improve communication between (business) partners $[5,13]$. While these benefits do seem very attractive they apparently have not yet convinced businesses to adopt 
governmental data delivery systems without hesitation. The majority of these systems support data streams related to so called information obligations, defined in Administrative Law. These data streams are vital to the functioning of governmental en societal processes. Tax filing, custom declarations, social security and employee information and statistics e.g. are the basis for policy making and the transfer of income and capital among citizens in a social constitutional state [14]. The top 10 of most voluminous business-to-government data streams in the Netherlands sum up to approximately 350 million messages a year.

For most businesses timely and accurate data delivery is a major burden. The investments for development and management of specific information systems make especially small and medium sized companies suffer under an administrative burden. In most Western European countries the administrative costs are estimated approximately $3 \%$ of the GNP which means that e.g. in the Netherlands the total of these administrative costs in 2004 was 17 billion euros. These costs hamper economic growth and employment [3].

Many countries try to develop their own solution by establishing effective and efficient electronic business-to-government interfaces. Finland e.g. introduced its TYVI system to support the delivery of financial data via private service providers. The E-CoRE project in Slovenia focussed on collection of raw data from enterprises. In Portugal business are legally obliged to send their tax file in a digital manner. And the Polish Complex Computer System for the Social Insurance Institute was an eEurope Award winner in 2005 [7]. Whereas governmental organizations invest in these electronic data exchange solutions and link them to administrative cost reduction programmes, the adoption rate and usage by businesses appears to be rather unpredictable. The Dutch Tax Administration e.g. has experienced rather poor adoption rates of its proprietary electronic filing applications (their edi-based and web/xml-based applications were eventually used by less then $5 \%$ of the focus group). Adoption rates of customs and agricultural import and export related systems are very high (with $95 \%$ electronic delivery rates of customs declarations). Given the mixed experiences after years of following a more lenient 'seduction policy' several governmental organizations have recently chosen to compel by law data delivery by businesses in an electronic manner.

This study is one of a series of studies which should help to understand the mechanisms behind the (non-)adoption of edi in business-to-government relationships. This topic has received little academic attention thus far despite the huge expenditures on governmental edi services. Furthermore, little empirical or theoretical work is done with respect to the role of the (private sector) intermediary organisations although these intermediates play an important role in the eGovernment domain. In every day practice a host of intermediary private parties such as accountancy firms, trading companies, or engineering bureaus handle contacts (including data reporting) with governmental agencies on behalf of their business clients.

In this study we examine the factors and strategies that influence the adoption of business-to-governmental data exchange applications by small and medium scale businesses, specifically in the context of the previously mentioned businesses information obligations. In the next paragraphs we present the theoretical 
background of our research, the research model and methodology that we used, and some preliminary results and their implications for practitioners and researchers.

\section{Theoretical background}

A vast volume on research regarding data interchange systems exists. This topic has been studied from various perspectives: a technical innovation perspective on the means of transporting messages, e.g. the Internet [2], a standardization perspective, e.g. on EDIFACT and XML standards, and an inter-organisational system perspective [11]. In her classification of research themes Henriksen shows, that the business value perspective of electronic data interchange is one of the dominating themes. Business value (especially operational performance and strategic performance) were the main perspectives in twenty articles in the 1991 to 2000 topfive journals on Management Information Systems (MIS).

In a recent meta-analysis of electronic data interchange (edi) research, based on sixty-eight articles from 34 journals over the period from 1993 to 2002, Elgarah [8] concludes that the main topics addressed were the general outcomes and benefits from edi (operational performances as you like) and the diffusion and implementation of edi. Much less attention was paid to strategy and edi adoption. Little or no attention was paid to governmental organisations as an electronic partner. Previously conducted studies mostly involved autonomous companies that use data exchange to communicate with their business partners.

Next to the diffusion and adoption of innovations theory [15], the transaction cost economics theory serves as theoretical basis in the analysis of electronic data exchange. The concept of markets and electronic markets [13] might help us to understand intermediation and dis-intermediation processes. The concept of hierarchies and electronic hierarchies is applicable to inter-organisational systems in general and to interchange systems in the governmental context specifically. The focus within hierarchies is on internal efficiencies rather than on the relationships between partners [8]. Governmental organisations have a natural tendency to put internal efficiency benefits first when developing data exchange systems [3]. Furthermore governmental bodies have the power to persuade or enforce adoption via e.g. licensing or legislation. Involuntary adoption and use may occur when mandated by the government $[8,10]$.

Many edi adoption research relates in some way to Roger's diffusion and adoption theory. Among the different aspects of the theory the five characteristics of the innovation: relative advantage, compatibility, complexity, triability and observability, are often used as variables in this type of adoption research. Given the specific characteristics of these data interchange systems, researchers have build extended models to analyse the specific dimensions of these inter organisational systems. These models contain, next to the (technological) characteristics of the innovation itself, variables on the organizational level and on the environmental level $[6,9,11,16,17]$. 
In addition to the financial management accounting focus [1] and the more recent focus on governmental management and policy making [14] we see the research on information logistics as another useful approach to the analysis of information obligation costs. Fundamental changes in the information logistics might have great (second order) effects on the efficiency and effectiveness of the organizations involved [5]. Intermediary parties as managers of these information chains play an important role. Especially small companies find it hard to derive full benefits from using data exchange systems. Integration and full implementation within their business processes is hardly being effected [6].

Confronted with pressure or legal regulation regarding the adoption of an electronic data exchange system, there is a third possible decision next to adoption and non-adoption: the outsourcing of electronic contact to a service provider or intermediary. We have not found any research on outsourcing as an adoption strategy. In the next paragraph we present a research model with first hypotheses founded in the theoretical context that we described .

\section{Research model: hypotheses and variables}

In this paragraph we present a conceptual model to guide our research on adoption factors in the business-to-government context. With Henriksen we choose a technological-indifferent approach to the subject of electronic data interchange [11]. Consequently in this study we do not differentiate between the traditional peer-topeer edi solutions and web-based solutions. In our practise we experience more or less the same adoption problems with both generations of systems. The overall model consists out of two sets of variables: adoption strategies and adoption factors (see figure 1). The adoption decision is the central element in the model. The adoption strategies result from the three possible outcomes of the adoption decision: adoption, non-adoption or outsourcing. We use the three main categories of adoption factors used in recent adoption research on electronic data interchange: the innovation-specific (technological), organisational and environmental characteristics.

The adoption factors influence the adoption decision.

Founded in the above presented theoretical background we formulate the following general hypotheses underlying the model:

Businesses adopt electronic data exchange systems with government under specific innovation-specific, organizational and environmental conditions. The outsourcing of this exchange is a relevant adoption strategy to many businesses. Organizational size and governmental pressure are important factors influencing that decision.

This hypotheses is based on the following arguments: small businesses are less able to gain operational performance (cost, quality) benefits in an electronic hierarchical relation with government, professional (intermediary) organizations can more easily integrate with government and benefit from the so called electronic integration effect [13]; these organizations can then market more and cheaper data exchange services based on their electronic linkage with governmental organizations. Especially when governmental (legal) pressure rises - when non-adoption is no longer tenable, smaller companies will outsource this data exchange relationship. 
The overall model and hypotheses are being explored, operationalized and tested in a current Ph.D. project. The model is in parallel being applied to three empirical studies, each focussing on a different subset of relations in the model.

This paper presents the results of one of these empirical projects, based on the partial model depicted in figure 1. The specific research model shows that we focus mainly on the relations between innovation-specific and organizational adoption factors and the outsourcing strategy. Other aspects of the model will also be addressed, but in a more qualitative manner.

In the next subparagraphs we separately address the two sets of variables used.

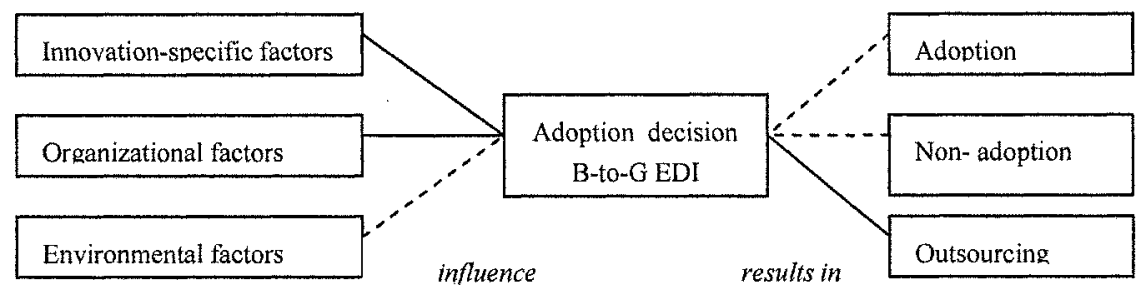

Fig. 1. The overall research model used in the Ph.D. -project of which this study is part of. The dotted lines represent relationships that were not included in this study.

\subsection{Adoption strategies}

Important phases in the adoption decision making process are knowledge gathering, persuasion, decision making, implementation and use of the innovation. A crucial moment in that process is the decision to adopt or reject (that is: non-adopt) the innovation. In this study we distinguish three adoption strategies: adoption, nonadoption and outsourcing.

Adoption is the result of a decision of an individual organisation "[to] make full use of an innovation at the best course of action available" [15]. Adoption is thus a mental or financial commitment towards the innovation or a physical acquisition of the artefact [11]. Chwelos uses the term "intend to adopt" to stress the fact that it exclusively concerns the initiation phase and not the implementation phase.

The possibility or intention of further integration and use within the organisation distinguishes adoption from the other two strategies: non-adoption and outsourcing.

Non-adoption is a rejection and reflects the decision not to adopt the innovation.

Outsourcing is the third adoption strategy. This strategy can be seen as a type of non-adoption decision: the organization has no intention of using (and possibly integrating) the innovation.

The three strategies also differ in the channels used for data delivery to government. Adoption leads to electronic delivery of messages by the individual 
business. Non-adoption in most cases leads to continuation of paper delivery by the business organization (contraire to the governments objective). Outsourcing means electronic delivery by an intermediary party.

\subsection{Adoption factors}

As stated earlier in this study we use the three layered technology-organizationenvironment model as a basis for research of the adoption decision. Many studies point at variables which go beyond Rogers' [15] innovation-specific characteristics: for instance organizational readiness, external pressure, competitive pressure and organization size $[6,9,11,12,16]$.

Based on the presented theory we expect five innovation-specific factors to play a role in the exploration and explanation of our hypotheses:

Cost savings (efficiency) as a specific relative advantage and operational performance characteristic [11]. Efficiency was mentioned as one motive for adoption of data exchange in ninety-seven percent of the studies examined in Elgarah's meta-analysis [8].

Reduction of error-rates as a specific relative advantage [6] and operational performance characteristic. The reduction of errors is directly related to the reduction of the information obligation costs.

Enhanced productivity (business process speed up) as a specific relative advantage. This factor resembles the "reduced lead time" factor of the operational performance focus by Henriksen [11].

Complexity as defined by Rogers. Complexity may hinder integration of (EDI-) applications and therefore will frustrate cost savings especially in the case of small and medium sized companies $[6,8,10]$.

Reduction of (cost of) outsourcing as a specific form of cost savings. This factor drives a possible dis-intermediation process [13] and is deliberately added because of its opposite direction to the hypothesized outsourcing strategy.

Based on the theory presented before we expect at least two organizational factors to play a role in the exploration and explanation of our hypotheses (due to practical constraints in the research plan we could not address more than two organizational factors):

Organizational size is often mentioned as a factor influencing the integration capabilities of an organisation and related to that the possibility to gain full benefits of EDI adoption $[6,8,11]$.

Organisational IT experience is a combination of IT (knowledge) related factors as IT sophistication [6] and technological resources [12]. It is mentioned as a factor influencing the integration capabilities of an organisation.

The theoretical environmental factors competitive pressure, industry life cycle or external pressure $[6,16]$ have not been operationalized and tested in this study. 


\section{Research methodology}

In January 2005 the Dutch Programme 'ICT and Reduction of the Administrative Burden' (ICTAL) performed a survey among individual businesses. This survey had the general objective to measure the perception towards governmental e-services and to focus specifically on electronic data interchange, reduction of the administrative burden and outsourcing specifically. We were involved in formulating the questions, and we could add specific questions needed for our purposes and afterwards we performed additional analyses on the data gathered.

\section{Operationalization}

The instrument used for the measurement of the various research variables is discussed below.

Outsourcing was measured in terms of the number of organisations that outsourced the handling of government services to a third party and in terms of the impact of the introduction of e-services on their outsource decision.

Cost savings, Reduction of error-rates, Enhanced productivity, Complexity, Reduction of (cost of) outsourcing were measured in terms of the perceived attitude in relation to the use of electronic data interchange with the government. (E.g. "Will the use of EDI enable your organization to save costs?")

Organizational size was measured in terms of the number of personnel working 15 hours per week or more.

Organisational IT experience was measured in terms of use of (specific) egovernment services during the last 12 months.

Furthermore some general questions were formulated on the themes electronic data interchange, reduction of the administrative burden and outsourcing.

\section{Data collection}

For our study a detailed questionnaire was developed that was based on the theoretical model discussed above, complemented by results from similar field studies and insights gained from interviews we did with entrepreneurs and civil servants. The specific questions for this study were drafted in such a way that they could be included in the earlier mentioned broader perception survey. The questions were related to the more general questions in order to make cross sectional analysis possible. The questionnaire was reviewed, tested and performed by a professional telephone survey organisation. The results of the study are based on a representative sample of small and medium scale business in the Netherlands; alas intermediary parties were not included in the survey. The net response for this study was 503 small and medium sized businesses. In case of a non-response the non-respondent was replaced with another business from the database matching the same characteristics in order to guarantee the representative character of the sample. The plain results of the survey have been published in [4]. 


\section{Sample characteristics}

The response is distributed evenly among business sectors and size. The respondents are e.g. from industry ( 9 percent), repair and trade (16\%), hotel and catering (19\%), distribution $(5 \%)$ and business services $(16 \%)$. Within the latter sector there is no bias towards ICT services. The response does contain a slight bias towards small firms: 62 percent of the respondents work in a company with less than ten employees, 90 percent of the companies has 50 employees or less.

\section{Results}

In this paragraph we present the main results of the data collection in terms of factors and relations. The results are presented into two themes: the perception of electronic data interchange with government, and the perception of outsourcing.

\subsection{Perception of electronic data interchange with government}

The general perception of businesses regarding the possible channels for electronic data delivery is presented in table 1 (the question was answered by a subset $(n=120)$ of the respondents - those businesses who had expressed a need for e-government services). We have related this general outcome to the organizational adoption factors.

Table 1, Most preferred electronic channel with government, source: [4]

\begin{tabular}{|l|r|}
\hline The Internet (web sites, e-mail) & $61 \%$ \\
\hline $\begin{array}{l}\text { Electronic data interchange with governmental organization } \\
\text { (business sends) }\end{array}$ & $23 \%$ \\
\hline $\begin{array}{l}\text { Electronic data interchange with governmental organization } \\
\text { (government fetches) }\end{array}$ & $3 \%$ \\
\hline Outsourcing to an intermediary party & $8 \%$ \\
\hline Non of the above options & $2 \%$ \\
\hline Do not know & $3 \%$ \\
\hline
\end{tabular}

With respect to the channels "edi, business sends" and "outsourcing" we calculated chi square to investigate the relations with organizational size and organizational IT experience. ${ }^{12}$

Neither for EDI, business sends" $\left(X^{2}=0.143\right)$ nor for "Outsourcing" $\left(X^{2}=0.080\right)$ a significant relation was found with organizational size. When a lower reliability level of $90 \%$ is used, a weak relation between "outsourcing" and organizational size was found: small business seem to have more tendency to outsource than larger ones.

With respect to the organizational IT experience there is a significant yet weak positive relation with "EDI business sends" $"$. Those businesses which prefer EDI as

${ }^{12}$ In all cases we used a reliability level of $95 \%$; thus $\mathrm{X}^{2}<0.05$ indicates a statistically significant relation. 
the electronic channel to the government have relatively more experience with governmental e-services than the others (the specific contact with the Tax Administration was used as a control variable).

Possible effects of electronic data interchange systems with government in term of the innovation-specific adoption factors have been formulated into five theses. Table 2 presents in percentages the perception of the respondents $(n=503)$ to these theses.

Table 2, Perceived effects of electronic data interchange systems with government, in terms of the innovation-specific adoption factors (in \%)

\begin{tabular}{|l|c|c|c|c|c|c|}
\hline $\begin{array}{l}\text { Adoption factor } \\
\text { /perception }\end{array}$ & $\begin{array}{c}\text { Totally } \\
\text { agree }\end{array}$ & $\begin{array}{c}\text { Mostly } \\
\text { agree }\end{array}$ & $\begin{array}{c}\text { Not agree, } \\
\text { not } \\
\text { disagree }\end{array}$ & $\begin{array}{c}\text { Mostly } \\
\text { disagree }\end{array}$ & $\begin{array}{c}\text { Totally } \\
\text { disagree }\end{array}$ & $\begin{array}{c}\text { Don't } \\
\text { know, no } \\
\text { meaning }\end{array}$ \\
\hline $\begin{array}{l}\text { Reduction of } \\
\text { crror- rates }\end{array}$ & 11 & 29 & 20 & 16 & 16 & 8 \\
\hline Cost savings & 12 & 31 & 15 & 18 & 15 & 9 \\
\hline Complexity & 15 & 17 & 12 & 25 & 24 & 7 \\
\hline $\begin{array}{l}\text { Enhanced } \\
\text { productivity }\end{array}$ & 14 & 31 & 16 & 13 & 19 & 7 \\
\hline $\begin{array}{l}\text { Reduction of } \\
\text { outsourcing }\end{array}$ & 14 & 31 & 16 & 13 & 19 & 7 \\
\hline
\end{tabular}

The results show a relatively positive attitude towards electronic data interchange with the government in terms of the innovation-specific adoption factors: 40 to $45 \%$ agrees with positive effects on the operational performance, $49 \%$ does not perceive complexity as an obstacle, and $44 \%$ of the respondents perceives possibilities to reduce (cost of) outsourcing. However a rather large group, approximately one third of the respondents, has a rather negative attitude towards the data interchange systems in this context.

Based on these results we investigated the relations between the perceived effects (innovation-specific factors) and organizational size and organizational IT experience, in terms of Pearson Chi-Square.

Table 3, Relations with perceived innovation-specific and organizational adoption factors

\begin{tabular}{|c|c|c|}
\hline Perceived factors & Organizational Size & IT Experience \\
\hline $\begin{array}{c}\text { Reduction of error- } \\
\text { rates }\end{array}$ & $\mathrm{X}^{2}=0.200(\mathrm{n}=498)$ & $\mathrm{X}^{2}=0.784(\mathrm{n}=359)$ \\
\hline Cost savings & $\mathrm{X}^{2}=0.002(\mathrm{n}=498)^{* * *}$ & $\mathrm{X}^{2}=0.848(\mathrm{n}=386)$ \\
\hline Complexity & $\mathrm{X}^{2}=0.000(\mathrm{n}=498)^{* * *}$ & $\begin{array}{c}\mathrm{X}^{2}=0.001 \\
(\mathrm{n}=408)^{* * *}\end{array}$ \\
\hline Enhanced productivity & $\mathrm{X}^{2}=0.086(\mathrm{n}=498)^{*}$ & $\mathrm{X}^{2}=0.244(\mathrm{n}=379)$ \\
\hline $\begin{array}{c}\text { Reduction of } \\
\text { outsourcing }\end{array}$ & $\mathrm{X}^{2}=0.172(\mathrm{n}=498)$ & $\mathrm{X}^{2}=0.305(\mathrm{n}=359)$ \\
\hline
\end{tabular}

${ }^{13} \mathrm{X}^{2}=0.043$, contingency coefficient $\mathrm{C}=0.355^{13}$ 
* $90 \%$ significance; *** $99 \%$ significance

One weak relationship and three strong ones exist. Large business somewhat agree more with the fact that electronic data interchange offers possibilities of enhanced productivity, small businesses do agree less. Large businesses do agree more with the fact that electronic data interchange offers possibilities of cost savings, small businesses do agree less. Small businesses do agree more with the fact that complexity hinders them to implement electronic data interchange, large businesses do agree less. The less IT experience the business has, the more it agrees; and visa versa.

\subsection{Perception of outsourcing}

The introduction of governmental e-services, e.g. electronic data interchange, could have an effect on the outsourcing decision. We measured how many business outsourced the handling of governmental services (Table 4), and what effect the introduction of governmental e-services would have on that outsourcing decision, (Table 5).

Table 4, Outsourcing percentage of the handling of governmental services $(n=503)$

\begin{tabular}{|l|c|}
\hline Business outsources (some) activities & $73 \%$ \\
\hline Business does not outsource activities & $26 \%$ \\
\hline Does not know & $1 \%$ \\
\hline
\end{tabular}

Table 5, Impact of introduction of governmental e-services on outsourcing decision $(n=503)$

\begin{tabular}{|l|c|}
\hline Leads to more outsourcing & $14 \%$ \\
\hline Leads to less outsourcing & $13 \%$ \\
\hline No change in outsourcing decision & $73 \%$ \\
\hline
\end{tabular}

Businesses which already outsourced have a greater tendency to outsource more than business which did not outsource yet. This is a statistically significant relationship. ${ }^{14}$ Additional analysis shows that there is a positive relation between "more outsourcing" and the perceived administrative costs $[4]^{15}$. Thus those organizations which indicate "more outsourcing" have the tendency to have a higher perception of administrative costs than other organizations.

\section{Conclusions}

Most of the conclusions confirm results of earlier studies in the business-to-business context. Apparently eGovernment does not (yet) bring forth new and specific adoption arguments.

In general, businesses have a positive perception of the possible benefits of data interchange with the government, especially in terms of operational performance.

${ }^{14} X^{2}=0.011 / C^{*}=0.147$

${ }^{15} \mathrm{X}^{2}=0.015 / \mathrm{C}^{*}=0.206$ 
Here, organizational size is the discriminating factor. Larger businesses in general have a more positive perception of potential cost savings and productivity enhancement than smaller businesses. Furthermore smaller businesses feel that complexity hinders them to implement electronic data interchange. This perception of complexity is also influenced by the IT experience of a business: the less IT experience the business has, the more it agrees with the thesis that complexity is hindering implementation. This is confirmed by the fact that those businesses which prefer edi as the electronic channel to the government have relatively more experience with governmental e-services than the others.

The results show some effects of the rather outspoken perception on possibilities and set backs of electronic data interchange with government on the adoption strategy chosen. Small business e.g. seem to have more tendency to outsource than larger ones. This seems to correspond with another finding in the same survey: the fact that smaller businesses are relatively less in need for governmental e-services [4]. Again organizational size is the discrimination factor. A possible explanation is the fact that smaller businesses perceive no opportunities gained from the "electronic integration effect" [13] with government. At the same time they do expect professional intermediary parties to benefit.

This explanation is supported by the fact that businesses which already outsourced have a greater tendency to outsource more (influenced by the introduction of governmental e-services) than business which did not outsource yet. Those businesses that outsource more have the perception that the introduction of interchange systems with government will lead to a reduction of (cost of) outsourcing. Here too the possible explanation is that these businesses expect professional intermediary parties to realize these cost benefits instead of realizing these effects for themselves.

\section{Implications}

This study presents a theoretical and empirical analysis of factors influencing the adoption strategies of business-to-government electronic data exchange systems. Outsourcing of this exchange is a relevant adoption strategy to many, especially smaller, businesses. One obvious question is how SMEs can realize a reduction of their administrative burden in this context.

In our opinion more attention should be given to the role of intermediary parties in these e-government services processes. These professionals in data logistics are better able to exploit the advantages of the electronic integration effect with the electronic government than individual (smaller) businesses. These intermediaries form a channel through which individual businesses can by reached electronically. The real challenge in that case for governmental organisations and individual companies is how to transfer the efficiency benefits gained by intermediaries into financial benefits (cost reduction) for individual (SME) companies. In our opinion competition plays an instrumental role. Two examples from the Dutch situation 
illustrate this market mechanism regarding eGovernment services. First of all we see the emergence of a totally new market of B-to-G electronic data interchange services offered by private application service providers (ASP's). These ASP's offer data transportation, data security and data management services to intermediaries and individual organisations, competing on quality and price. Secondly, large accountancy firms are currently offering their individual business clients a $20 \%$ reduction on their bills related to electronic filing of annual accounts (which tries to meet the $25 \%$ reduction objective of the administrative burden formulated by the Dutch government). Following this strategy intermediary parties can become helpful partners in the implementation of qualitative and cost effective eGovernment services.

A successful introduction of B-to-G electronic data exchange services asks for the right balance of governmental efficiency benefits, intermediary services, and the reduction of the administrative burden of individual businesses. The factors influencing these adoption strategies are hardly understood yet. We will elaborate and empirically test our theoretical model further. We are currently investigating the implications of legal enforcement of electronic tax filing in the Netherlands. Since the government will probably benefit most from the increased efficiency the legitimacy of the legal enforcement of electronic data exchange might be(come) questioned. In this respect the government should have a thorough understanding of the innovation adoption mechanism before taken bold and irreversible steps.

\section{References}

1. Allers, Administrative and Compliance Costs of Taxation and Public Transfers in the Netherlands, dissertation, Rijksuniversiteit Groningen, June (1994).

2. R. Angeles, Revisiting the role of Internet-EDI in the current electronic commerce scene, Logistics Information Management, Volume 13 (1), 2000, pp. 45-57.

3. R. Arendsen, T.M. Engers, van, Reduction of the Administrative Burden: an egovernment perspective, Third International Conference EGOV 2004, Springer, 2004.

4. F.R. Bongers, R.A. Te Velde, C. Holland, Entrepreneurs on public electronic services, (Dialogic, Utrecht, February 2005).

5. E. Brynjolfsson, L.M. Hitt, Beyond Computation, in: Inventing the Organisations of the $21^{\text {st }}$ Century, ed: Malone, T.W., (The MIT Press, Cambridge. Massachusetts, 2004).

6. P. Chwelos, I. Benbasat, A.S. Dexter, Research Report, Empirical Test of an EDI Adoption Model, (Information Systems Research, September 2001).

7. EIPA, eEurope Awards for eGovernment 2005, (Winners, www.eipa.nl, 2005). 
8. W. Elgarah, J. Falaleeva, C.S. Saunders, Data Exchange in Interorganizational Relationships, (The Database for Advances in Information Systems, Vol.36, Winter 2005).

9. R.T. Frambach, H. Schillewaert, Organizational innovation adoption: a multilevel framework of determinants, (Journal of Business Research, 55 (2), 2002).

10. Hart, P., Saunders, C., Power and Trust: Critical Factors in the Adoption and Use of Electronic Data Interchange, Organization Science, 8 (1), 1997, 23-42.

11. H.Z. Henriksen, Performance, Pressure and Politics, Ph.D. dissertation, Department of Informatics, (Copenhagen Business School, March 2002).

12. C.L. Iacovou, I. Benbasat, A.S. Dexter, Electronic Data Interchange and Small Organizations: Adoption and Impact of Technology, in (MIS Quarterly, December 1995).

13. T.W. Malone, J. Yates, R.I. Benjamin, Electronic Markets and Electronic Hierarchies, (Communications of the ACM, Vol.30, Number 6, June 1987).

14. Nijssen, Dansen met de octopus, English Summary,( Eburon, Delft, 2003).

15. E.M. Rogers, (Diffusion of Innovations, Fifth edition, (Free Press, New York, 2003).

16. L.G. Tornatzky, M. Fleicher, The Process of Technological Innovation, Lexington Young Books, 1990).

17. K Zhu, K.L. Kraemer, S, Xu, A Crosss-Country Study of Electronic Business Adoption, (Twenty-Third International Conference on Information Systems, 2002). 